4. Транспонирование матрицы онлайн [Электронный ресурс] URL: https://matrix.reshish.ru/transpose.php (дата (дата обращения 05.12.2021).

5. Отраслевой портал «Российское судоходство» [Электронный ресурс] URL: https://russhipping.ru/ru/infstruct/news/?id=42546/ (дата обращения 03.12.2021)

6. Губа О.П. Бухгалтерская отчётность как значимый инструмент оценки сбалансированности развития предприятий морского транспорта /О.П.Губа, Е.С. Севостьянова, А.А. Штепа А.А.// Символ науки: международный научный журнал. -2020 - № 3. - С. $36-43$.

\title{
Степанова Т.А., Кустова Е.С. \\ Анализ показателей, характеризующих ликвидность и платежеспособность предприятия на примере ООО «Феникс» Каменского района Воронежской области
}

Воронежский государственный аграрный университет имени Императора Петра I doi: 10.18411/trnio-01-2022-104

(Россия, Воронеж)

\section{Аннотация}

В данной статье проводится анализ платежеспособности и ликвидности на примере коммерческой организации ООО «Феникс» Каменского района Воронежской области.

Ключевые слова: финансовое состояние предприятия, платежеспособность предприятия, показатели ликвидности, активы предприятия, экономическая и финансовая стабильность.

\section{Abstract}

This article analyzes solvency and liquidity on the example of a commercial organization Phoenix LLC, Kamensky District, Voronezh Region.

Keywords: the financial condition of the enterprise, the solvency of the enterprise, liquidity indicators, the assets of the enterprise, economic and financial stability.

Ликвидность или текущая платежеспособность — индикатор состояния дел компании. Она определяется как уровень компенсации обязательств компании с помощью ее активов. При этом время трансформации активов в деньги равен отведенному для погашения задолженности периоду.

Следует обратить внимание, что сама по себе высокая платежеспособность не всегда говорит о выгодных вложениях средств в оборотные активы, значит, говорить о полной идентичности терминов все же рискованно. На практике чаще всего используется такое разделение понятий: ликвидность - потенциальная способность предприятия рассчитываться по своим обязательствам, платежеспособность - реальная возможность выполнять взятые на себя обязательства. Ликвидность имеет отношение к движению фондов, а платежеспособность - движению денег.

Ликвидность относится к одним из основных экономических понятий, которое отражает экономическую и финансовую стабильность предприятия. Под ликвидностью активов понимается способность их быстрой продажи по рыночной цене. Анализируя платежеспособность предприятия, производятся расчеты по определению ликвидности активов предприятия и ликвидности баланса предприятия.

Группировка статей баланса ООО «Феникс» Каменского района Воронежской области отражена в таблице 1.

Таблица 1

Группировка статей актива и пассива для анализа ликвидности баланса в ООО «Феникс» Каменского района Воронежской области

\begin{tabular}{|c|c|c|c|c|}
\hline Показатели & $\begin{array}{c}\text { На начало } \\
2020 \text { года }\end{array}$ & $\begin{array}{c}\text { На конеи } \\
2020 \text { года }\end{array}$ & $\begin{array}{c}\text { Отклонение } \\
(+,-)\end{array}$ & $\begin{array}{c}\text { Темп } \\
\text { прироста, } \\
\%\end{array}$ \\
\hline A & 1 & 2 & 3 & 4 \\
\hline Актив & 87494 & 124906 & 37412 & 42,76 \\
\hline
\end{tabular}




\begin{tabular}{|c|c|c|c|c|}
\hline $\begin{array}{c}\text { А1 Высоколиквидные активы - (денежные } \\
\text { средства и краткосрочные финансовые } \\
\text { вложения) }\end{array}$ & 1384 & 20594 & 19210 & 1388,01 \\
\hline $\begin{array}{c}\text { А2 Среднеликвидные (быстрореализуемые) } \\
\text { активы - (дебиторская задолженность и } \\
\text { прочие активы) }\end{array}$ & 3309 & 1681 & -1628 & $-49,20$ \\
\hline $\begin{array}{c}\text { АЗ Низколиквидные (медленно и } \\
\text { труднореализуемые) активы - (товары, } \\
\text { готовая продукция, другие } \\
\text { производственные запасы, незавершённое } \\
\text { производство, а также "Долгосрочные } \\
\text { финансовые вложения" (1 раздел Актива) } \\
\text { кроме вложений в уставные фонды) }\end{array}$ & 39891 & 35082 & -4809 & $-12,06$ \\
\hline $\begin{array}{c}\text { A4 Неликвиды (внеоборотные активы, } \\
\text { кроме долгосрочных финансовых вложений) }\end{array}$ & 42910 & 67549 & 24639 & 57,42 \\
\hline П. Пассив & 87494 & 124906 & 37412 & 42,76 \\
\hline $\begin{array}{c}\text { П1 Наиболее срочные (до } 3 \text { месячев) } \\
\text { (кредиторская задолженность, ссуды, не } \\
\text { погашенные в срок, прочие пассивы) }\end{array}$ & 721 & 855 & 134 & 18,59 \\
\hline $\begin{array}{l}\text { П2 Краткосрочные пассивы (3-6 мес. до } \\
\text { года) (краткосрочные кредиты и займы) }\end{array}$ & 0 & 0 & 0 & - \\
\hline $\begin{array}{c}\text { ПЗ Долгосрочные пассивы (до года и более) } \\
\text { (долгосрочные кредиты и займы) }\end{array}$ & 0 & 12793 & 12793 & - \\
\hline $\begin{array}{c}\text { П4 Постоянные пассивы (собственный } \\
\text { капитал и резервы) }\end{array}$ & 86773 & 111258 & 24485 & 28,22 \\
\hline
\end{tabular}

Суть анализа ликвидности баланса заключается в сравнении средств по активу, сгруппированных по степени их ликвидности и расположенных в порядке убывания их ликвидности, с обязательствами по пассиву баланса, сгруппированных по срокам их погашения и расположенных в порядке возрастания сроков. Баланс считается ликвидным, если имеют место соотношения, представленные в таблице 2 в графе 1.

На 2020 год у предприятия ООО «Феникс» Каменского района Воронежской области наиболее срочные обязательства ниже наиболее ликвидных активов согласно данным таблицы 2. Остальные группы также соответствуют нормативным требованиям.

Таблиия 2

Анализ ликвидности баланса ООО «Феникс»

\begin{tabular}{|c|c|c|}
\hline Модель ликвидности & Ha 1.01.2020 2. & Ha 1.01.2021 2. \\
\hline$A_{1 \geq \Pi_{1}}$ & $A_{1(1384)}>\Pi_{I(721)}$ & $A_{1(20594)}>\Pi_{l(855)}$ \\
\hline$A_{2} \geq \Pi_{2}$ & $A_{2(3309)}>\Pi_{2(0)}$ & $A_{2(1681)}>\Pi_{2(0)}$ \\
\hline$A_{3} \geq \Pi_{3}$ & $A_{3(39891)}>\Pi_{3(0)}$ & $A_{3(35082)}>\Pi_{3(12793)}$ \\
\hline$A_{4} \leq \Pi_{4}$ & $A_{4(42910)<} \Pi_{4(86773)}$ & $A_{4(67549)<\Pi_{4(111258)}}$ \\
\hline
\end{tabular}

По результатам сравнения активов и пассивов можно сделать вывод о том, что баланс ООО «Феникс» на 1 января 2021 г. абсолютно ликвиден. Это означает, что активов предприятия достаточно, чтобы покрыть все обязательства, то есть финансовых ресурсов хватает, чтобы погасить долги в необходимый срок.

Помимо абсолютных показателей ликвидности и платежеспособности, существуют также и относительные в виде коэффициентов.

Различные относительные показатели ликвидности и платежеспособности представляют интерес для потребителей аналитической информации: коэффициент абсолютной ликвидности - для поставщиков сырья и материалов; коэффициент быстрой ликвидности - для банков; коэффициент текущей ликвидности - для покупателей и держателей акций и облигаций предприятия.

В таблице 3 представлен расчет показателей ликвидности средств ООО «Феникс». 
Таблиия 3

Коэффициентный анализ ликвидности средств предприятия

\begin{tabular}{|c|c|c|c|c|}
\hline Показатели & $\begin{array}{c}\text { На } \\
\text { начало } \\
2020 \text { 2. }\end{array}$ & $\begin{array}{l}\text { На конеи } \\
2020 \text { г. }\end{array}$ & $\begin{array}{c}\text { Отклонение } \\
(+,-)\end{array}$ & $\begin{array}{l}\text { Теоретически } \\
\text { достоверно }\end{array}$ \\
\hline$A$ & 1 & 2 & 3 & 4 \\
\hline 1. Коэффиииент абсолютной ликвидности & 1,92 & 24,09 & 22,17 & $0,20-0,25$ \\
\hline $\begin{array}{l}\text { 2. Коэффиииент срочной ликвидности } \\
\text { (промежуточный коэффициент покрытия) }\end{array}$ & 6,51 & 26,05 & 19,54 & $0,7-0,8$ \\
\hline $\begin{array}{l}\text { 3. Коэффициент текущей ликвидности } \\
\text { (общиий коэффициент покрытия) }\end{array}$ & 61,84 & 67,08 & 5,25 & $1,5-2,5$ \\
\hline $\begin{array}{l}\text { 4. Коэффичиент обеспеченности } \\
\text { собственными оборотнными средствами }\end{array}$ & 0,98 & 0,99 & 0,01 & 0,1 \\
\hline $\begin{array}{l}\text { 5. Коэффициент утраты } \\
\text { платежеспособности }\end{array}$ & - & 34,20 & - & 1,0 и более \\
\hline
\end{tabular}

Подводя итог вышесказанному, можно сделать следующие вывод о том, что предприятие ООО «Феникс» Каменского района Воронежской области является экономически и финансово стабильным, так как.

1. При сравнении активов и пассивов была выявлена абсолютная ликвидность баланса на 1 января 2021 г.

2. Коэффициент абсолютной ликвидности выше нормы, что свидетельствует о возможности погашения краткосрочных кредитов за счет высоколиквидных активов.

3. Коэффициент срочной ликвидности выше нормы, что свидетельствует об устойчивости финансового состояния.

4. Коэффициент текущей ликвидности превышает рекомендуемое значение, что говорит о платежеспособности предприятия.

5. Коэффициент утраты платежеспособности значительно выше 1. Это говорит о том, что анализируемое предприятие в ближайшие три месяца не утратит своей платежеспособности.

Предприятие ООО «Феникс» Каменского района Воронежской области является хорошим примером экономической устойчивости и финансовой стабильности, которых в Российской Федерации не так уж много.

$$
* * *
$$

1. Степанова Т.А. Определение типа финансовой устойчивости как основа успешного функционирования предприятия / Т.А. Степанова, Ю.А. Евсюкова // Уральский научный вестник. - 2017. - Т. 9. - № 1. - С. 021026.

2. Панина Е.Б. Обеспеченность сельскохозяйственных предприятий Воронежской области оборотными активами и эффективность их использования / Е.Б. Панина, С.А. Чернышова, И.В. Бичева // Молодежный вектор развития молодежной науки: материалы 70-й студенческой научной конференции. - Ч. IV. - Воронеж: ФГБОУ ВО Воронежский ГАУ, 2019. - С. 247 - 253.

3. Сурков И.М. Финансовый анализ в коммерческих организациях: учебное пособие / И. М. Сурков, В. А. Лубков, Д. Н. Литвинов. - Воронеж: Издательско-полиграфический центр "Научная книга", 2016. - 186 с.

4. Измайлова Л.Н. Оценка перспектив развития коммерческой деятельности / Л.Н. Измайлова, Т.А. Степанова // Финансовая экономика. - 2019. - №6. - С.556-560. 